\title{
Research on Visual Design Based on Mobile Internet - Taking E-book APP as an Example
}

\author{
Wei Liu ${ }^{1, a}$ \\ ${ }^{1}$ Fujian Jiangxia University, Fuzhou, Fujian, China, 350001 \\ a57858152@qq.com
}

Keywords: Mobile Internet; E-book; APP visual design

\begin{abstract}
With the continuous development of science and technology, mobile Internet plays an increasingly important role in people's daily life. The scale of Mobile Internet users are growing greatly, mobile Internet has become the focus of the current global information industry competition, its development has brought endless application space for the mobile network. The rise of e-books, breaking the people's regular way of reading. How to rationalize the visual design and help the electronic reading to be better communicated and developed under the technical support of the mobile Internet is the urgent problem to be solved in the development of modern digital reading.
\end{abstract}

\section{Introduction}

Broad defined mobile Internet refers to the general term of new information media relying on digital, network information processing technology and communication network forming after World War II. On the narrow sense, the mobile Internet is the general term of the various new media forming after the World War II, relying on digital, networked, civil information processing technology and communication network, led by professional information network organizations, and a variety of digital information processing terminal are treated as output device, through providing large-scale interactive information and entertainment services for users to obtain economic benefits. With the development of the times, current mobile Internet is more refers to personalized instant messaging carrier where the mobile phone is treated as the audition terminal, while mobile Internet as a platform. With the development of science and technology and people's life fashion, more and more people fall in love with the e-book reading, firstly, an e-book can take full advantage of leisure and waiting time, secondly, the cost of e-books are much lower than the price of books, and even some novels APP is not to pay any fees, which bring convenience and more fun for people who loving reading to some extent. Even when having lunch, the modern young people can log in the websites and forums to browse the news, and participate in hot topic discussion, e-book became a partner in the rest time. When coming back home from company until going to bed they will have part of the time to browse the network information, because of the fast pace of life, modern young people only use fragmented time to read here and there.

\section{Project Requirement Analysis}

\section{E-Book APP Status Quo}

With the development of the times, the progress of science and technology. More and more traditional ways of transmission were eliminated, and a group of emerging media is emerging. Mobile Internet is applying the way of the Internet model, using electronic data and article technology, Internet technology, through the network, satellite, mobile terminals, digital television and other means to spread the information. At the same time, with the arrival of the mobile Internet era, if its unique communication, space, scientific characteristics can be combined with electronic reading reasonably, then it will strongly spread electronic reading information, can also make the subjective initiative to accept digital reading innovation and creativity, making it easier for the public to accept. The definition of the term mobile Internet by scholars in media industry is also different, the definition of the mobile Internet is broad and no fixed boundaries. Mobile Internet produced is not based on nothing, the mobile Internet produced is based on the "old" and traditional 
media expression, that is, that newspapers, radio, television and other traditional media people often say. The mobile Internet apply the way of the Internet model, using electronic data and article technology, Internet technology, through the network, satellite, mobile terminals, digital television and other means to spread. However, the emergence of electronic reading, its innovative and creative content is difficult to be accepted and recognized by the public, most of the electronic reading works are eliminated due to narrow communication channels and a single mode of transmission. Therefore, how to use the technical advantages of mobile Internet, combining with visual design, to help electronic reading to be better spread and developed is problem to be solved for the development of modern digital reading.

\section{Differences between E-Books and Traditional Paper Books}

At the mobile Internet era, using scientific and technological means to achieve a wide range of inclusive and large amount of information that cannot be completed by the traditional media, expression form of e-book can be described as a very comprehensive, diversified, the spread can be achieved through the network, mobile phone terminals, and other channels and a variety of digital tools. Every Internet user on the Internet can become the publisher of the original information and the recipient of the information. In the traditional paper books, people can only receive the information traditional paper books bring for us, and the meaning of mobile Internet is not only able to receive a lot of information, and we can use the Internet at any time to publish and communicate with others through different aspects of interaction, which is essentially changing the way people read. In addition, the establishment of e-books is based on mobile Internet, and traditional paper books are limited to publications, the two information package capacity have a great difference. In the establishment and improvement of the database process, mobile Internet also expand the information space. In the past regular and quantitative information dissemination method, we can ensure the retention of information and expand the coverage of information. From the daily timing of quantitative reception of information to be able to choose their own time to receive the information. Different with the fixed and monotonous transmission method of the traditional media that cannot make interaction and communication realize very good. Mobile Internet based on Internet and mobile platform can make people read anytime, anywhere, without having to be limited to the name of the book, the time of reading, and so on.

\section{E-Book App Influencing Factors}

For e-book APP, the impact factors are more extensive. Because if an e-book APP gets successful development and operation, it needs to experience the creation, initial establishment, start using, user feedback and other stages and all aspects of adjustment and observation. But reviewing the influence of e-book APP factors, most of the factors are not the impact of e-book APP itself, for example, in the process of software development, the bug of program leads to the e-book APP cannot work properly; In the process of adjusting and probation period, due to software failure, resulting in e-book APP cannot successfully provide effective information. However, the biggest impact of e-book APP is derived from the user's feedback, and only when the user access to the ebook APP itself, then they can give the feedback information, therefore, for e-book APP, how to make the user at the first time, long-term and continuously use APP is the issue that the product designer should consider. Then, the problem will point to the visual design.

Visual design as the first impression of an e-book APP leaving users, that is, whether the e-book APP can attract the attention of users; whether the e-book APP can meet the user's preferences; Whether color and interface of design e-book APP can meet the user's reading habits, to meet the needs of users and so on. In the e-book APP visual design, the interface design, including the layout of the interface, layout, color are the primary influencing factors; while graphic layout design is the second largest visual design factors. Therefore, for e-book APP designers, they not only need to develop a complete and smooth software program, more importantly, how to meet the user's reading needs to design the interface to brighten users' eyes. 


\section{The Project Design}

\section{E-Book Icon Design}

For an APP, the first way making the reader and the user have the impression and the first memory is its icon. A good APP application software icon design is often able to retain customers, also created its existence value and market value. Good icon design can make people shine and want to have a try. The e-book icon design should not be bound by the traditional cultural concept, but should show the modern atmosphere and cultural characteristics. As the recent WeChat reading of Bigfire, "micro-reading". Its icon design is mainly based on warm colors, firstly make people's vision have a better comfort, and second there is a close affinity in which people can quickly accept and recognize.

\section{E-Book Home Page Design}

Open an App application software, the first to see is the App home page interface, this interface can explain the main features and features of this APP, so the APP home page interface experience will affect the users' follow-up experience to the product. Mobile APP home page interface should be able to highlight the main features and characteristics of the product. Mobile phone APP home page interface should be automatically updating according to the actual situation, such as when you start a game App, it will often find this app will be adjusted according to different festivals, or according to the application function to increase the corresponding presentation adjustment, so that each user will feel very intimate when re-opening the mobile phone APP after updating the software, able to advance with the times.

In the e-book home page, the reader can click to find the page, can see the search and recommend novel options, the user can choose the novel their want to read and download, when the user choose to download, there will be downloaded links for users to choose, and the user's every download novel will be showed in the cloud download records of personal information page when user log in APP.

In general, e-books can provide customers with two records of their own reading books and reading progress in local cache and online cloud. Users can click on the local novel having been downloaded to read and complete the novel, and then read the content, the user can read through the directory and chapters for selective reading, after each reading, you can set a bookmark, convenient for reading, besides, text can also be set, besides, the font size and color can be set as well.

\section{E-Book Personal Information Page Design}

In the design of personal information page, in general, the user first need to use APP to carry out the user registration, you can log in through the third party QQ software, of course, you can use the phone to register, when you have completed the registration, you can view their own download novels, you can also upgrade the software and view the use of help.

\section{E-Book Graphic Design}

Graphic reading interface not only have the text or the picture, you can combine the text with picture, and also add video, music and other dynamic effects, in particular, adding the dynamic music and video into it, you can show APP's personalized and functional more vividly, of course, when adding these rich media audio and video, you should also consider the loading speed, you can install the music video loaded into the installation package, otherwise the slow speed of the network request will lead to greatly decline of user experience.

\section{APP Interface Visual Design Analysis}

In visual design, "vision" is the core of visual design. For the "vision", the most important of which is the "visual symbols", "visual symbols" as the basic design element of visual design, existing in all aspects of human life, the object that as long as the human eye can see and identify can be used as a "visual symbol", such as: the trees on the street, the surrounding buildings, all kinds of goods, also including the stage performances, music songs, text symbols, as long as the objects that human eye can see and identify are the design elements of the visual communication design. Therefore, in the APP interface visual design, we should focus on the "visual symbols" of the design of the interface, such as: the main function symbols in APP interface, allowing users to clearly and intuitively understand the main function of the APP, how can get the information you 
want by clicking on which part in the process.

\section{Project Achievement}

\section{Feasibility Analysis}

If you count the mobile phone newspaper and other MMS class reading media, the penetration rate of mobile phone readers in China will be more than 30 percent, that is, more than 200 million users. With the popularity of smart phones for Chinese, and now almost the phone in the hands of everybody can download APPs with the general capacity, and the memory of e-books occupation is not large, a hundred pages of e-books only occupy only dozens of KB, which means that users can download a lot of their favorite e-books, so they can choose the local novel to read in their own spare time.

And China's APP development technology is more and more mature, an APP prototype will be able to be completed by a four to five members team after half a month, coupled with the late amendments and loopholes, the entire APP development cycle will not be more than 2 months, which bring great convenience to the APP market. Especially the novel class APP, the development cost is low, conductive to occupy the early market. And most of the novels in APP are free of charge, users can freely download and read, but a small part of the novel in charge, as long as the amount of user downloading is high, the basic income can reach a break even, planting game ads in the APP is the main source of income.

\section{Development Advantages Analysis}

Compared with "old" media, mobile Internet is not a separate existence of the media, it is using the Internet to integrate all the traditional media, the same information dissemination channels become more and as well the feedback. In the mobile Internet environment, electronic reading communication will become more flexible, with full media, full-time, diversity, world, equality and so on. In the process of electronic reading and communication, in the process of transmission, the spread form is not only rigidly adhere to the text + picture, while may appear the combination text + picture + video + audio and other performance carriers; and the audience not only obtain fun through newspapers, books, they can also use smart phone to read. Electronic reading content is no longer like the monotonous mode of traditional information, but equipped with Internet terminals, the audience can always browse through the Internet information at any time, access to the contents of the book that they want to understand.

\section{Conclusion}

E-book APP is able to fit the modern young people and people's Internet reading habits, but also bring fragmented reading opportunities for the people who love to read but don't have time to read, I believe that as long as people we can start from the fundamental needs, continuously improve and change the visual design of APP to improve the user's reading experience, e-book APP will be able to reflect its own value.

Fund Project: Fujian Jiangxia Institute 2015 Youth Research Talent Cultivation Fund Project "Research on Visual Interaction Design of the Mobile Internet Application Model Construction" Project No. : JXS2015017

\section{References}

[1] Yang Mengyuan. Research on App advertising interactive design [D]. Zhejiang University of Technology. 2014

[2] Dai Fuping. Discussion on the "visual flow" in the layout design [J]. Decorative .2014 (07)

[3] Lu Zhao. Cross-border virtual function of graphic design- take the design of "Budapest Hotel" as an example [J]. Decorative .2014 (08)

[4] Chen Xinghai, He Renke, Yang Huan. Research on the innovation model of business model 
under design thinking - Taking MIUI as an Example [J]. Decorative .2014 (08)

[5] Peng Quyun. The visual form design innovation under cross-boundary thinking [J]. Yihai, 2015 (07).

[6] Jiang Wenling. APP interactive design based on design courseware [D]. Southwest Jiaotong University. 2014

[7] Li Yamin. The new context of visual communication design in the information age [J]. Green Technology, 2015 (08).

[8] Wang Lin. Brand communication new media-brand APP interface design research and exploration [D]. Donghua University 2014 